\title{
Strategi Meningkatkan Daya Saing dan Upaya Bertahan Saat Pandemi Covid-19 Pada PT Sasak Maiq Batu Layar Lombok Barat
}

\author{
Ida Bagus Eka Artika ${ }^{1}$ Irianto $^{2}$, Ida Ayu Ketut Marini ${ }^{3}$, Baiq Ertin Helmida ${ }^{4}$ \\ ${ }^{1,3}$ Universitas Mahasaraswati Denpasar Kampus PSDKU Mataram \\ ${ }^{2,4}$ Sekolah Tinggi Ilmu Ekonomi AMM
}

\begin{abstract}
The sustainability of PT Sasak Maiq, in West Lombok Regency, is currently facing a threat with the emergence of the Covid-19 pandemic which began to hit Indonesia in early 2020. PT Sasak Maiq is worried about this, because it has an impact on the decline in sales turnover of their products. This requires strategic studies, both in order to increase business competitiveness, as well as strategies to be able to maintain the existence of SMEs during the Covid-19 pandemic, which cannot be predicted when it will end. This type of research is descriptive to find out which strategies are suitable to be applied in order to maintain the existence of PT Sasak Maiq in the future, especially during the current Covid-19 pandemic. The data collection method is the case method, with an analytical technique in the form of environmental analysis (SWOT Analysis). The results of the study show that a strategy that is suitable to be applied in maintaining the sustainability of PT Sasak Maiq in the future is the ST strategy, or a strategy that utilizes strengths to minimize existing threats, namely in the form of a diversification strategy, by creating unique new products, strengthening online marketing networks, maintain the pricing strategy, keep in touch with the marketing network both at home and abroad, in order to maintain demand for its products.
\end{abstract}

Keywords: SWOT analysis; diversification strategic; covid-19 pandemic

\begin{abstract}
Abstrak
Keberlanjutan PT Sasak Maiq, di Kabupaten Lombok Barat, saat ini menghadapi ancaman dengan kemunculan pandemi Covid-19 yang mulai melanda Indonesia pada awal tahun 2020. PT Sasak Maiq mengkhawatirkan hal ini, karena berdampak terhadap penurunan omzet penjualan produk mereka. Hal ini memerlukan kajian strategis, baik dalam rangka meningkatkan daya saing usaha, maupun strategi untuk bisa mempertahankan keberadaan UKM selama pandemic Covid-19, yang tidak dapat diramalkan kapan berakhirnya. Jenis penelitian adalah deskriptif untuk mengetahui strategi yang cocok diterapkan dalam rangka mempertahankan keberadaan PT Sasak Maiq di masa mendatang, khususnya di masa pandemic Covid19 yang sedang berjangkit saat ini. Metode pengumpulan data adalah metode kasus, dengan teknik analisis berupa analisis lingkungan (SWOT Analysis). Hasil penelitian adalah strategi yang cocok diterapkan dalam mempertahankan keberlanjutan PT Sasak Maiq di masa mendatang adalah strategi ST, atau strategi yang memanfaatkan kekuatan untuk meminimalisir ancaman yang ada, yaitu berupa strategi diversifikasi, dengan cara menciptakan produk-produk baru yang unik, memperkuat jaringan pemasaran online, mempertahankan strategi harga, tetap menjalin hubungan dengan jaringan pemasaran baik di dalam maupun luar negeri, demi mempertahankan permintaan produknya.
\end{abstract}

Kata kunci: analisis SWOT; strategi diversifikasi; pandemi covid-19

\footnotetext{
${ }^{1}$ Penulis koresponden. guseka960@gmail.com
} 


\section{PENDAHULUAN}

Usaha kecil dan menengah (UKM) merupakan usaha produktif yang ditekuni oleh masyarakat kecil, yang tumbuh dari kelompok-kelompok usaha yang dibentuk di suatu daerah dengan produk-produk unggulan untuk dikembangkan. Kelompok-kelompok ini kemudian mendapat pembinaan dari pihak pemerintah, melalui program-program pemberdayaan sehingga produktivitas masyarakat dapat ditingkatkan melalui pengembangan produk-produk unggulan di daerah tersebut. Kelompok-kelompok usaha ini kemudian diharapkan tumbuh menjadi usaha kecil dan menengah yang produktif dan berkembang, sehingga akan menjadi unit-unit usaha kecil yang dapat memperkuat perekonomian masyarakat. Dalam kenyataannya yang terjadi di Indonesia, usaha kecil dan menengah merupakan entitas ekonomi produktif yang tahan banting, walaupun kondisi ekonomi sedang kurang baik.

Mempertahankan keberlangsungan usaha merupakan suatu keniscayaan bagi pelaku bisnis, karena dengan terjaganya kelangsungan hidup usaha, maka harapan untuk meningkatkan nilai usaha akan terjaga. Meningkatnya nilai usaha akan berdampak jangka panjang baik bagi pemilik usaha, pekerja pada usaha tersebut maupun konsumennya, sehingga akan mendatangkan kesejahteraan bagi masyarakat.

Semua upaya untuk meningkatkan nilai perusahaan, tidak terlepas dari strategi yang diteapkan oleh perusahaan, baik itu strategi pemasaran maupun strategi dalam meningkatkan daya saing produk. Craven (2018), menyatakan bahwa "Strategi pemasaran didefinisikan sebagai analisis strategi pengembangan dan pelaksanaan kegiatan dalam strategi penentuan pasar sasaran bagi produk pada tiap unit bisnis, penetapan tujuan pemasaran, dan pengembangan, pelaksanaan, serta pengelolaan strategi program pemasaran, penentuan posisi pasar yang dirancang untuk memenuhi keinginan konsumen pasar sasaran“.

Menurut Kotler (2012), dalam mendesain suatu strategi pemasaran, hal terpenting yang perlu dilakukan oleh manajemen pemasaran adalah penerapan konsep STP (Segmentasi Pasar, Target Pasar, Posisi Pasar). Konsep ini saling terkait satu sama lainnya, secara garis besar adalah sebagai berikut: 1). Segmentasi Pasar, yaitu mengindentifikasikan variabel segmentasi pasar dan mensegmentasi pasar; serta mengembangkan gambaran segmen yang dihasilkan, 2). Target Pasar, yaitu mengevaluasi daya tarik masing-masing segmen dan memilih segmen pasar yang tepat, dan 3). Posisi Pasar, yaitu mengidentifikasi konsep positioning yang memungkinkan bagi masing-masing segmen pasar, kemudian memilih mengembangkan dan mengkomunikasikan konsep positioning tersebut.

Selanjutnya Porter (2012) menyatakan strategi bersaing adalah pencarian posisi bersaing yang menguntungkan di dalam suatu industri, arena fundamental tempat persaingan terjadi. Strategi bersaing bertujuan menegakkan posisi yang menguntungkan dan dapat dipertahankan terhadap kekuatan-kekuatan yang menentukan persaingan industri.

Salah satu pendekatan yang berguna untuk merumuskan strategi bisnis adalah analisis kompetitif dari Porter (2012), yang didasarkan pada analisis terhadap lima kekuatan bersaing, yaitu: masuknya pesaing baru, ancaman dari produk pengganti (substitusi), kekuatan tawar menawar pembeli, kekuatan tawar menawar pemasok serta persaingan antar perusahaan yang ada di dalam industri. Gabungan dari kelima kekuatan inilah yang sesungguhnya menentukan posisi laba akhir dalam suatu industri. Strategi yang diterapkan untuk mencapai keunggulan kompetitip yang berkelanjutan terdiri dari lima strategi, yaitu: differensiasi, biaya rendah, fokus, preemption dan sinergi (Aaker, 2017).

Usaha Kecil dan Menengah (UKM), PT. Sasak Maiq adalah salah satu kelompok usaha kecil dan menengah yang berkembang dengan baik di Desa Senteluk, Kecamatan Batulayar, Kabupaten Lombok Barat, dimana UKM ini berhasil mengembangkan produk-produk hasil laut menjadi produk olahan yang laku dijual, khususnya kepada wisatawan sebagai produk oleh-oleh khas Lombok. Produk-produk yang dihasilkan, yang merupakan produk unik untuk oleh-oleh 
khas dari Lombok berupa aneka camilan berbasis olahan hasil pertanian dan rumput laut, seperti tortilla, kopi rumput laut, rengginang rumput laut, stick rumput laut, berbagai permen, terasi, camilan dari jagung, dan lain-lain. Keunikan produk-produk dari PT. Sasak Maiq ini menjadi salah satu daya tarik bagi wisatawan, baik wisatawan domestik maupun asing untuk membeli produk-produk yang dihasilkan sebagai oleh-oleh khas dari Lombok.

PT. Sasak Maiq telah menjadi oase ekonomi pesisir terutama kelompok perempuan yang diperkuat pemerintah Lombok Barat, atas dukungan Kementerian Kelautan dan Perikanan (KKP) melalui program pemberdayaan masyarakat yang dikenal sebagai Coastal Community Development Project (CCDP) yang dilaksanakan sejak tahun 2013. (Azis, 2017). Sebagai salah satu usaha yang mendapat pembinaan dari pemerintah, produk-produk yang dihasilkan oleh PT. Sasak Maiq juga berkesempatan beberapa kali diikutkan pameran di luar negeri seperti di Inggris, sebagai salah satu upaya memperkenalkan produk olahan pangan dari Indonesia di pasar global (Turmuzi, 2018).

Srategi pemasaran, merupakan salah satu kunci yang harus dikuasai oleh PT. Sasak Maiq dalam mempertahankan keberlanjutan usahanya, di tengah kondisi ekonomi yang lesu, akibat adanya pandemi Covid-19, yang telah melanda Indonesia sejak awal tahun 2020. Strategi pemasaran yang diterapkan haruslah juga diikuti oleh usaha meningkatkan daya saing produknya, sehingga usaha tersebut dapat bertahan dalam kondisi ekonomi yang semakin terpuruk akibat pandemic Covid-19 yang melanda Indonesia, bahkan seluruh dunia saat ini. Mengingat pentingnya strategi pemasaran, penelitian ini bertujuan untuk menentukan strategi yang dilakukan oleh PT Sasak Maiq dilihat dari faktor internal dan eksternal perusahaan untuk meningkatkan daya saing produknya. Disamping itu penelitian ini bertujuan untuk mengetahui upaya yang dilakukan oleh PT. Sasak Maiq untuk bisa bertahan pada masa pandemi Covid 19 ini.

\section{METODE PENELITIAN}

Penelitian ini bersifat deskriptif (Soegiyono, 2015) yaitu penelitian yang dilakukan untuk melakukan pemecahan masalah pada saat sekarang, melalui pengumpulan dan pengolahan data kemudian melakukan penarikan kesimpulan. Penelitian dilakukan dengan cara melakukan analisis lingkungan eksternal dan internal untuk mendapatkan alternatif strategi, dalam meningkatkan daya saing produk-produk UKM PT Sasak Maiq agar keberlanjutan Usaha Kecil Menengah tersebut tetap dapat dipertahankan.

Penelitian dilakukan di UKM PT Sasak Maiq, sebagai salah satu Usaha Kecil Menengah yang beralamat di Dusen Penyanget, desa Senteluk, Kecamatan Batulayar, Kabupaten Lombok Barat. PT. Sasak Maiq dipilih sebagai lokasi penelitian karena perusahaan ini merupakan perusahaan yang cukup baik berkembang sebelum adanya pandemi Covid-19 dengan daerah pemasaran yang relatif luas.

Data dalam penelitian ini berupa data primer yang diperoleh dengan melakukan pengamatan langsung ke pt Sasak Maiq dan melakukan wawancara dengan pihak PT Sasak Maiq dan konsumen dari PT Sasak Maiq, dan data sekunder, yaitu data yang berdasarkan dokumen tertulis yang diperoleh dari pihak PT Sasak Maiq Kabupaten Lombok Barat.

Metode pengumpulan data yang dilakukan, yaitu dengan studi lapangan yang dilakukan untuk mendapatkan data yang akurat dengan melakukan observasi yaitu melakukan pengamatan langsung ke objek penelitian, yaitu PT. Sasak Maiq, yang berlokasi di Dusun Penyanget, Desa Senteluk, Kecamatan Batulayar, Kabupaten Lombok Barat dan interview yaitu melakukan wawancara dengan pihak PT Sasak Maiq yaitu dengan Baiq Siti Suryani sebagai pendiri sekali gus direktur PT. Sasak Maiq.

Analisis data, menggunakan analisis SWOT yang merupakan salah satu metode untuk menggambarkan suatu kondisi dan mengevaluasi suatu masalah, proyek atau konsep bisnis yang berdasarkan faktor internal dan faktor ekternal yaitu strengths, weakness, opportunities dan 
threats (Rangkuti, 2011). Analisis faktor-faktor Internal terdiri dari sumberdaya yang dimiliki, kapabilitas dan kompetensi inti, yang mempengaruhi kinerja perusahaan dibandingkan dengan kondisi-kondisi di lingkungan eksternal. Faktor-faktor internal akan mengidentifikasi kekuatan dan kelemahan dari perusahaan. Analisis lingkungan eksternal adalah berbagai faktor di luar perusahaan yang dapat merupakan peluang atau ancaman bagi perusahaan. Suatu peluang adalah kondisi dalam lingkungan umum yang dapat membantu suatu perusahaan mencapai daya saing strategis. Suatu ancaman adalah kondisi dalam lingkungan umum yang dapat menghambat usaha-usaha perusahaan untuk mencapai daya saing strategis.

SWOT matrix menggambarkan berbagai alternative strategi yang dapat dilakukan oleh perusahaan yang didasarkan pada hasil analisis SWOT. Dari matrik ini akan dihasilkan empat alternatif pilihan strategi, yaitu: Strategi SO, yaitu strategi yang digunakan dengan memanfaatkan kekuatan yang dimiliki untuk memanfaatkan berbagai peluang yang ada. Strategi WO adalah strategi dengan meminimalisir kelemahan untuk memanfaatkan berbagai peluang yang ada. Strategi ST adalah strategi dengan mamanfaatkan kekuatan untuk mengurangi berbagai ancaman. Strategi WT yaitu dengan mengurangi berbagai kelemahan untuk menghindari ancaman yang dihadapi.

\section{HASIL DAN PEMBAHASAN}

Sesuai dengan permasalahan yang ingin dipecahkan dan tujuan penelitian yang ingin dicapai, pembahasan penelitian ini terdiri dari analisis faktor-faktor internal dan analisis lingkungan eksternal, atau disebut dengan analisis SWOT. Dari analisis yang dilakukan, diharapkan akan diperoleh suatu formulasi strategi yang tepat untuk diterapkan oleh PT Sasak Maiq, agar bisa unggul dalam bersaing khususnya di musim pandemic Covid-19 yang sedang melanda semua wilayah di dunia saat ini.

\section{Analisis Faktor-faktor Internal}

Analisis faktor-faktor internal, terdiri dari dua unsur penting, yaitu unsur kekuatan dan unsur kelemahan yang dimiliki oleh PT Sasak Maiq, dimana untuk mengidentifikasi kedua unsur tersebut, peneliti mengumpulkan pendapat dan fakta-fakta dari narasumber yang relevan, khususnya dari pihak perusahaan.

Beberapa faktor kekuatan yang dimiliki antara lain, 1). Memiliki pasar yang strategis, yaitu berupa pasar online, yang jangkauannya melewati batas daerah propinsi bahkan batas negara, 2). Memiliki produk-produk yang unik, sebagai oleh-oleh khas dari Pulau Lombok, 3) Akses perusahaan (lokasi) yang mudah dijangkau, 4) Menjadi usaha binaan oleh pemerintah baik pemerintah daerah (Dinas Perikanan dan Kelautan Lombok Barat) dan juga Kementerian Kelautan dan perikanan Pusat, 5). Bahan baku produk yang mudah dicari dan tersedia dalam jumlah relative banyak, dan 6). Perusahaan memiliki jaringan yang luas, khususnya di bidang pemasaran, dengan pihak-pihak yang bergerak di bidang pariwisata.

Sementara yang menjadi faktor kelemahan, yaitu: 1). Fasilitas untuk perdagangan online masih belum maksimal, 2). Pemanfaatan media online dalam mempromosikan produk belum maksimal, 3). Keterbatasan tenaga terampil untuk proses produksi, manajemen dan pemasaran, 4). Sarana produksi masih manual/penggunaan mesin terbatas, 5). Belum memiliki standar penjaminan mutu produk.

\section{Analisis Lingkungan Eksternal}

Adapun analisis lingkungan eksternal bertujuan untuk mengidentifikasi faktor-faktor peluang dihadapi oleh PT. Sasak Maiq, antara lain: 1). Pihak perusahaan bisa memanfaatkan berbagai platform di pasar online untuk menarik konsumen, 2). PT Sasak Maiq bisa membuka gerai yang khusus menjual produk-produk yang unik, sebagai oleh-oleh khas dari Lombok/Mataram, 3). PT. Sasak Maiq tetap bisa menjalankan usahanya, baik berproduksi 
maupun melakukan pemasaran di masa Pandemi Covid-19 dengan tetap menerapkan protokol kesehatan yang disarankan pemerintah, 4). Meningkatkan pelayanan dalam penjualan produk secara online, untuk memuaskan konsumen dan menciptakan loyalitas konsumen.

Adapun faktor ancaman yang dialami yaitu 1). Kondisi perekonomian yang lesu akibat terjadinya pandemi Covid-19, 2). Daya beli masyarakat menurun, sehingga masyarakat mengutamakan membeli kebutuhan pokok, 3). Kedatangan wisatawan yang berkunjung ke Pulau Lombok menurun karena adanya pandemi Covid-19, 4). Kondisi pandemi yang berkepanjangan mengancam perusahaan tidak berproduksi lagi, karena tidak adanya permintaan produk dari konsumen.

\section{Evaluasi Analisis SWOT}

Evaluasi terhadap Analisis SWOT dilakukan berdasarkan hasil penilaian aspek-aspek internal maupun eksternal, dengan membuat bobot dan skor setiap aspek yang telah dinilai, untuk menentukan nilai setiap indikator yang ada, melalui tabel EFAS (external factor analysis summary) dan IFAS (internal factor analysis summary).

Hasil evaluasi faktor-faktor internal menunjukkan penilaian terhadap indikator-indikator kekuatan dan kelemahan pada PT. Sasak Maiq, sebagai berikut :

Tabel 1. Identifikasi Faktor-faktor Internal PT Sasak Maiq

\begin{tabular}{lccc}
\hline \multicolumn{1}{c}{ Faktor-Faktor Internal } & Bobot & Rating & Bobot x Rating \\
\hline Kekuatan : & & & \\
1. Memiliki Pasar online (strategis) & 0,08 & 4 & 0,32 \\
2. Produk unik, sebagai oleh-oleh khas Lombok & 0,08 & 3 & 0,24 \\
3. Lokasi Perusahaan Strategis & 0,09 & 4 & 0,36 \\
4. Mendapat Binaan dari Instansi pemerintah & 0,09 & 4 & 0,36 \\
5. Bahan baku mudah didapat & 0,09 & 3 & 0,27 \\
6. Memiliki jaringan yang luas, di bidang- & & & 0,40 \\
$\quad$ pemasaran & 0,10 & 4 & 1,95 \\
\hline \multicolumn{1}{c}{ Total Skor Kekuatan } & & \\
\hline
\end{tabular}

\begin{tabular}{llll} 
Kelemahan : & & & \\
1. Fasilitas perdagangan online masih terbatas & 0,09 & 4 & 0,36 \\
2. Pemanfaatan media online belum maksimal & 0,10 & 2 & 0,20 \\
3. Keterbatasan tenaga terampil & 0,09 & 3 & 0,27 \\
4. Proses produksi masih manual & 0,09 & 2 & 0,18 \\
5. Belum ada standar penjaminan mutu produk & 0,08 & 4 & 0,32 \\
\hline \multicolumn{2}{c}{ Total } & 1,00 & \\
\hline
\end{tabular}

Sumber: Data primer, diolah. 2021

Dari hasil evaluasi analisis faktor-faktor internal, ternyata bahwa skor kekuatan sebesar 1,95 lebih tinggi dibandingkan dengan skor kelemahan yaitu 1,33. Ini merupakan suatu hal yang positip, karena masih terdapat faktor-faktor yang dapat digunakan sebagai kekuatan untuk mempertahankan keberadaan PT. Sasak Maiq ke depan.

Pada evaluasi faktor-faktor eksternal dilakukan penilaian indikator-indikator yang berhubungan dengan peluang dan tantangan/ancaman yang dihadapi oleh PT. Sasak Maiq di Kabupaten Lombok Barat. Dilihat dari tabel 2, indikator faktor-faktor eksternal, skor peluang pada PT. Sasak Maiq, Kabupaten Lombok Barat berada pada posisi 1,35 lebih rendah dari faktor ancaman yaitu sebesar 1,60. Lebih jelasnya dapat dilihat pada tabel 2 berikut. 
Tabel 2. Identifikasi Analisis Faktor-Faktor Eksternal Pada PT. Sasak Maiq

\begin{tabular}{lccc}
\hline \multicolumn{1}{c}{ Faktor-Faktor Strategi Eksternal } & Bobot & Rating & Bobot x Rating \\
\hline Peluang : & & & \\
1. Terdapat berbagai platform di pasar online & 0,15 & 3 & 0,45 \\
2. Membuka gerai untuk pasar oleh-oleh & 0,10 & 4 & 0,40 \\
3. Tetap dapat berusaha di masa pandemic Covid-19 & 0,10 & 2 & 0,20 \\
4. Meningkatkan pelayanan produk secara online & 0,10 & 3 & 0,30 \\
\hline \multicolumn{2}{c}{ Total Skor Peluang } & & 1,35 \\
\hline
\end{tabular}

Ancaman

1. Perekonomian lesu akibat pandemi Covid-19 $\quad 0,15 \quad 4 \quad 0,60$

2. Daya beli masyarakat menurun $\quad 0,15 \quad 3 \quad 0,45$

3. Kunjungan wisatawan menurun di masa pandemi $0,10 \quad 2 \quad 0,20$

4. Pandemi covid-19 berkepanjangan yang$\begin{array}{llll}\text { mengancam keberlanjutan perusahaan } & 0,15 & 3 & 0,45\end{array}$

\begin{tabular}{cccc} 
Total & 0,15 & 3 & 0,45 \\
\hline
\end{tabular}

Sumber: Data primer, diolah, 2021

\section{Strategi yang Disarankan}

Untuk mendapat gambaran yang lebih jelas tentang posisi strategisnya, kedua hasil evaluasi tersebut selanjutnya akan digambarkan dalam diagram analisis SWOT. Nilai evaluasi internal menunjukkan nilai kekuatan sebesar 1,95-1,33 yaitu sebesar 0,62 ke arah faktor kekuatan, dan nilai evaluasi eksternal menunjukkan posisi panah ke bawah atau ancaman sebesar $1,60-1,35$ yaitu sebesar 0,25 .

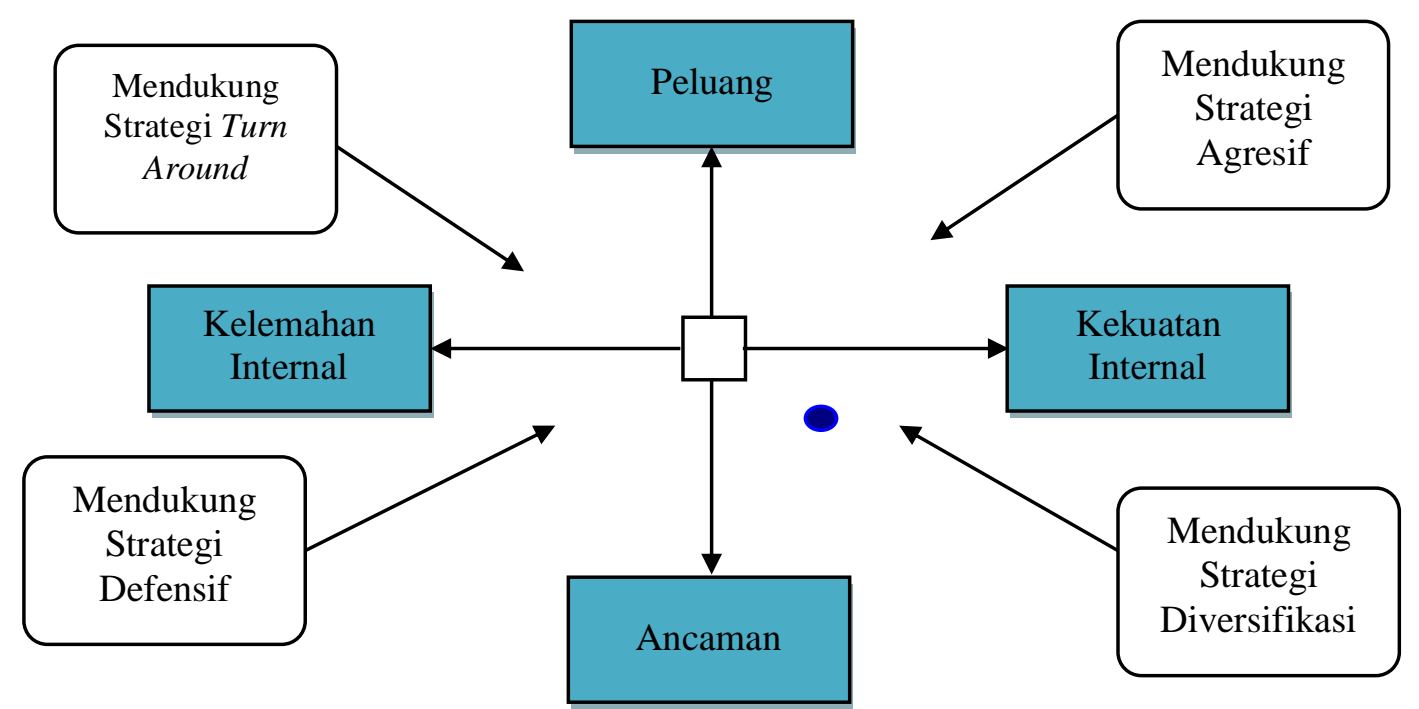

\footnotetext{
Gambar 1. Posisi Strategis PT Sasak Maiq berdasarkan Analisis SWOT

Sumber: Data Primer, diolah, 2021

Keterangan $=0$ Tanda Posisi Bersaing PT. Sasak Maiq pada kuadran 2.
}

Dengan melihat posisi strategis PT Sasak Maiq Kabupaten Lombok Barat berdasarkan evaluasi faktor-faktor internal dan lingkungan eksternal, maka posisinya berada pada kuadran yang mendukung strategi diversifikasi, karena PT Sasak Maiq Kabupaten Lombok Barat memiliki kekuatan untuk meminimalisir tantangan/ancaman yang dihadapi.

Hasil evaluasi faktor internal dan lingkungan eksternal tersebut dijabarkan ke dalam matriks SWOT berikut: 
Gambar 2. Matriks SWOT PT Sasak Maiq Kabupaten Lombok Barat

\begin{tabular}{|c|c|c|}
\hline $\begin{array}{l}\text { S } \\
\text { W } \\
\text { O }\end{array}$ & \begin{tabular}{ll}
\multicolumn{1}{c}{ Kekuatan (S) } \\
1. \\
Memiliki Pasar online \\
(strategis) \\
2. Produk unik, oleh-oleh \\
khas Lombok \\
3. Lokasi Perusahaan \\
Strategis \\
4. Mendapat binaan dari \\
Instansi pemerintah \\
5. Bahan baku mudah \\
didapat \\
6. Memiliki jaringan yang \\
luas, di bidang pemasaran
\end{tabular} & $\begin{array}{l}\text { Kelemahan (W) } \\
\text { 1. Fasilitas perdagangan } \\
\text { online masih terbatas } \\
\text { 2. Pemanfaatan media } \\
\text { online belum maksimal } \\
\text { 3. Keterbatasan tenaga } \\
\text { terampil } \\
\text { 4. Proses produksi masih } \\
\text { manual } \\
\text { 5. Belum ada standar } \\
\text { penjaminan mutu produk }\end{array}$ \\
\hline $\begin{array}{l}\text { Peluang (O) } \\
\text { 1. Terdapat berbagai } \\
\text { platform di pasar online } \\
\text { 2. Membuka gerai untuk } \\
\text { pasar oleh-oleh } \\
\text { 3. Tetap menjalankan } \\
\text { usaha pada masa } \\
\text { pandemic Covid-19 } \\
\text { 4. Meningkatkan } \\
\text { pelayanan produk } \\
\text { secara online }\end{array}$ & $\begin{array}{l}\text { Strategi SO } \\
\text { Gunakan kekuatan yang } \\
\text { dimiliki untuk menangkap } \\
\text { peluang yang ada agar dapat } \\
\text { meningkatkan profitabilitas }\end{array}$ & $\begin{array}{l}\text { Strategi WO } \\
\text { Tanggulangi kelemahan } \\
\text { yang dimiliki untuk } \\
\text { menangkap peluang yang } \\
\text { ada. }\end{array}$ \\
\hline $\begin{array}{l}\text { Ancaman (T) } \\
\text { 1. Perekonomian lesu } \\
\text { akibat pandemi Covid- } \\
19 \\
\text { 2. Daya beli masyarakat } \\
\text { menurun } \\
\text { 3. Kunjungan wisatawan } \\
\text { menurun di masa } \\
\text { pandemic } \\
\text { 4. Pandemi covid-19 } \\
\text { berkepanjangan yng } \\
\text { mengancam } \\
\text { keberlanjutan } \\
\text { perusahaan }\end{array}$ & $\begin{array}{l}\text { Strategi ST* } \\
\text { - Gunakan kekuatan yang } \\
\text { dimiliki untuk } \\
\text { meminimalkan ancaman, } \\
\text { yaitu dengan } \\
\text { menenciptakan produk- } \\
\text { produk baru yang unik, } \\
\text { - Memperkuat jaringan } \\
\text { pemasaran online, } \\
\text { mempertahankan strategi } \\
\text { harga, tetap menjalin } \\
\text { hubungan dengan jaringan } \\
\text { pemasaran baik di dalam } \\
\text { maupun luar negeri, agar } \\
\text { bisa mempertahankan } \\
\text { permintaan produk- } \\
\text { produknya. }\end{array}$ & $\begin{array}{l}\text { Strategi WT } \\
\text { Minimalkan kelemahan } \\
\text { untuk mengatasi ancaman } \\
\text { yang dihadapi }\end{array}$ \\
\hline
\end{tabular}

Sumber: Tabel 1 dan 2

Berdasarkan analisis IFAS, EFAS dan matriks SWOT yang dihasilkan maka Strategi yang disarankan untuk meningkatkan daya saing PT Sasak Maiq Kabupaten Lombok Barat adalah 
strategi ST, yaitu strategi yang mendukung strategi diversifikasi, yaitu dengan menggunakan kekuatan yang ada untuk meminimalisir ancaman yang dihadapi.

\section{SIMPULAN}

Dari hasil analisis faktor lingkungan (SWOT) dihasilkan satu alternatif strategi yaitu strategi ST yang mendukung strategi diversifikasi, dimana faktor kekuatan yang ada dapat meminimalisir ancaman yang dihadapi, dan yang harus dilakukan oleh PT Sasak Maiq adalah dengan cara menciptakan produk baru yang unik, memperkuat jaringan pemasaran online, mempertahankan strategi harga, tetap menjalin hubungan dengan jaringan pemasaran baik di dalam maupun luar negeri, agar bisa mempertahankan permintaan produk-produknya.

Dari kajian yang telah dilakukan, khususnya pada PT Sasak Maiq di Kabupaten Lombok Barat, dapat disarankan dua hal berikut: 1) untuk mendukung strategi ST yang harus diterapkan oleh PT Sasak Maiq di Kabupaten Lombok Barat, maka pihak perusahaan perlu minta dukungan kepada pemerintah, yaitu dinas terkait seperti Dinas Perikanan dan Kelautan, Dinas Koperasi dan UMKM, khususnya dalam hal pembinaan-pembinaan di bidang pemasaran online. 2). Tetap menjaga hubungan baik dengan pemangku kepentingan, yaitu para pelanggan dan pemasok bahan baku, untuk menjamin keberlangsungan perusahaan di masa mendatang.

\section{DAFTAR PUSTAKA}

Aaker, David A. (2017), Strategic Market Management, $11^{\text {th }}$ Edition, John Wiley \& Sons, Inc, New York, USA.

Azis, Kamarudin (2017), Oase Ekonomi Itu Sasak Maiq, http://www.denun89.wordpress.com)

Cravens, David W. (2018) Strategic Marketing, $8^{\text {th }}$ ed, Pierce Book Sales Strategic, Alih Bahasa, Lina Salim, Penerbit Erlangga, Jakarta.

Kotler, Philip (2012), Marketing Management, $15^{\text {th }}$ Edition, Prentice Hall, Inc. New Jersey 07458 (Alih Bahasa: Drs. Benyamin Molan, Manajemen Pemasaran, PT. Prenhallindo, Jakarta.

Nazir, Moh. (2011) Metode Penelitian, Ghalia Indonesia, Jakarta

Porter, Michael E. (2012), Keunggulan Bersaing, Menciptakan dan Mempertahankan Kinerja Unggul, Alih Bahasa, Tim Penerjemah Binarupa Aksara, Binarupa Aksara Jakarta.

Rangkuti, Freddy, (2011), Analisis SWOT, Teknik Membedah Kasus Bisnis, PT Gramedia Pustaka Utama, Jakarta.

Sugiyono, (2015), Metode Penelitian Bisnis, Penerbit CV. Alfabeta, Bandung.

Turmuzi (2018), Sasak Maiq, dari Usaha Rumahan Hingga Beromzet Ratusan Juta, (https://www.cendananews.com ) 